\title{
PORNOGRAFÍA EN TELEVISIÓN SIN HORARIO RESTRINGIDO
}

\section{PORNOGRAPHY ON TELEVISION WITHOUT RESTRICTED \\ HOURS}

Maribel Martínez Eder: Portavoz de FIATYR (Federación Ibérica de Telespectadores y Radioyentes) mm.eder@asociacionplazadelcastillo.org

\section{CURRÍCULUM VITAE}

Fundadora y presidenta de la Asociación Plaza del Castillo ATR Navarra de Usuarios de Medios de Comunicación, integrante de FIATYR (Federación Ibérica de Asociaciones de Telespectadores y Radioyentes). Fue miembro del Consejo Asesor de RTVE en Navarra.

\section{RESUMEN}

La pornografía se muestra cada vez de forma más explícita en los medios de comunicación. El problema es que a estos, cada vez tienen más acceso los niños. Y el problema es mayor aún en el caso de la televisión, en el que la publicidad y los programas no se esconden de la programación en horario supuestamente reservado para los menores.

\section{PALABRAS CLAVE}

Pornografía - Televisión - Niño

\section{ABSTRACT}


Pornography is increasingly more explicitly in the media. The problem is that these, are becoming more accessible to children. And the problem is even greater in the case of television, where advertising and programs do not hide from the primetime supposedly reserved for children.

\section{KEY WORDS}

Pornography - TV - Child

\section{TEXTO}

En España, a nadie parece importarle el hecho de que la pornografía y la publicidad de la prostitución campen por sus respetos en televisión, en las revistas que se reparten gratuitamente con el periódico correspondiente, o en los anuncios de contactos de los más importantes rotativos.

Recuerdo cuando en 2005, siendo miembro del Consejo Audiovisual de Navarra, tuve que contactar con altos cargos del Ministerio de Ciencia y Tecnología; reconocían la existencia, por toda la geografía española, de en torno a mil emisoras ilegales, emitiendo pornografía dura en abierto. Quiere decir que aparte de otras consideraciones, mil emisoras emitían sin licencia.

Al no existir en España una Autoridad Audiovisual, no hay a día de hoy, persona u organismo, incluidos los consejos audiovisuales autonómicos (Cataluña, Navarra y Andalucía), que tenga conocimiento, a ciencia cierta, de las emisoras que siguen 
emitiendo tales contenidos en esas condiciones, y no parecen preocuparse por ello. Nada desearía más que estar equivocada.

Desde las asociaciones de usuarios de medios de comunicación, como estudiosos de los medios, no nos limitamos a analizarlos desde el punto de vista del espectador. Nuestra posición, intentando ir al fondo de la cuestión, es la siguiente:

Sabemos que la oferta va por delante de la demanda, que entra gratis en nuestras casas, y que tal cosa supone la existencia de una maquinaria gigantesca de crear contenidos.

Para alimentar al monstruo, deben proporcionarse, forzosamente, miles de horas de celuloide, textos, fotos.

Cada vez se trabaja un material más duro, menores incluidos, que precisa desarrollarse en un mundo sórdido de abuso, donde se inculcan todos los derechos, por no decir abiertamente delictivo (lo demuestran las crónicas de sucesos y las redadas de pederastas que día sí y día no, pueblan los informativos. Por supuesto, relacionado con la trata de blancas, el proxenetismo y la desaparición y el abuso de menores.

Aparte de lo que ocurre en nuestro país, ¿no nos apercibimos de que miles de niños y jóvenes del Este de Europa y de los países del tercer mundo, generalmente sin recursos de ningún tipo, en manos de auténticas mafias, viven en medio de una sordidez sin salida?

Frecuentemente desaparecen o mueren, para que sea posible que en Occidente no falte la ración diaria de contenidos aberrantes. 
Es evidente que, por no complicarse la vida, responsables políticos y mediáticos, jueces y magistrados, periodistas y tertulianos de toda ideología, pasan sobre ello, como sobre ascuas. Aunque quizá fuera más justo decir que no les importa absolutamente nada. Tampoco se molestan las feministas, los teóricos del maltrato, de la violencia sexual, o de la desaparición de menores.

Prostitución a la carta.

Según la Gaceta de los Negocios (Grupo Negocios) de 7 de Marzo de 2008:

"Los periódicos siguen lucrándose con la prostitución a pesar del Congreso"

"La prensa en España "se forra con la prostitución" La Gaceta, Público y Avui son lo únicos diarios que vetan la publicidad de contactos".Quisiera añadir: El Diario de Navarra. Es de justicia reconocer que, por no traspasar ciertos límites, dejan de ganar mucho dinero.

En el mismo artículo, añade La Gaceta de los Negocios, que los socialistas pedirán que se supriman los anuncios de contactos sexuales en la prensa española ya que la prostitución está íntimamente ligada al tráfico de mujeres.

Ojalá pudiéramos creerles, a los socialistas, digo, también prometieron poner en marcha la Ley del Audiovisual (Autoridad independiente incluida), cuando accedieron al poder en 2004.El proyecto de ley debe de estar guardado en un cajón con el contento de UTECA* y la desesperación de los usuarios.

*UTECA (Unión de televisiones comerciales asociadas), Antena3; Telecinco; Canal+, Quatro, La Sexta, Net tv, VEO. 
Sigue informando La Gaceta:

"El País ingresa, por éstos conceptos, más de 6 millones de euros al año". El resto de la prensa en la misma proporción.

El día 6 de Marzo de 2008:

El País publicó 855 anuncios de contactos.

El Mundo, 491.

ABC, 200.

La Razón, 109.

La Vanguardia, 443.

El Periódico, 414.

Por si fuera poco, el periódico La Razón, (que viene acaparando lectores de ABC, proclives simplificando, al conservadurismo y a la monarquía), regala los sábados la revista ¡Qué me dices! de Hachette-Filipacci. Pues bien, el ejemplar del 8 de Marzo pasado, trae, entre una publicidad indescriptible, la foto de una persona que parece ser una niña de unos 15 años. Teniendo en cuenta que claramente se percibe que proviene de algún país donde se desarrollan antes, puede que tenga en torno a trece. Texto: "negritas viciosas, verás que cositas hacen." ¿Verdad que suena terrible?

Pamplona-Madrid. Abril 2008. 